\title{
Squamous Cell Carcinoma of the Middle Ear Mimicking CSOM with Intracranial Complications: A Diagnostic Dilemma
}

\author{
Anoop Attakkil, Vandana Thorawade, Mohan Jagade, Rajesh Kar, Kartik Parelkar, \\ Poonam Khairnar, Reshma Hanowate, Devkumar Rangaraja
}

Department of ENT, Grant Medical College \& Sir J.J. Hospital, Mumbai, India

Email: fasttrack2317@gmail.com

Received 20 September 2014; revised 15 October 2014; accepted 11 November 2014

Academic Editor: Mostafa Bakry, ENT Sleep Well Clinic \& Noor Hospital, Bahrain

Copyright (C) 2014 by authors and Scientific Research Publishing Inc.

This work is licensed under the Creative Commons Attribution International License (CC BY). http://creativecommons.org/licenses/by/4.0/

(c) 7 Open Access

\begin{abstract}
Cancer of the external auditory canal (EAC) and middle ear (ME) is rare, accounting for less than 1\% of all head-and-neck malignancies [1] [2] of which squamous cell carcinoma (SCC) is the most common. Even though squamous cell carcinoma [SCC] of the middle ear and chronic suppurative otitis media (CSOM) co-exist, no definitive correlation has been proven. Here we are presenting a case of squamous cell carcinoma of the middle ear who presented with headache, fever and vomiting with a background history of chronic suppurative otitis media since childhood. A provisional diagnosis of mastoid abscess with intracranial complications secondary to chronic suppurative otitis media was made and modified radical mastoidectomy was done but histology of the mastoid specimen revealed well differentiated keratinizing squamous cell carcinoma, which was treated with radical radiotherapy. Objective of this presentation is to bring attention to the coexistence of CSOM and squamous cell carcinoma ear and also the importance to detect these lesions at an early stage. This report also highlights the requirement of histopathological analysis in mastoidectomy and discusses the aetiology and management of squamous cell carcinoma of the middle ear with review of literature.
\end{abstract}

\section{Keywords}

Squamous Cell Carcinoma, Mastoid, Otitis Media 


\section{Introduction}

Cancer of the external auditory canal (EAC), the middle ear (ME) and the mastoid is fortunately rare. Its incidence has been estimated as 1 case per every 5000 - 20,000 patients admitted to hospitals with otological diseases [3]-[5] or as 6 cases per million in the general population [6]. Squamous cell carcinoma accounts for the most common histologic type in this region, occurring in more than $80 \%$ of cases [7] [8].

The major etiological factor is chronic suppurative otitis media (CSOM) [9]-[12] although irradiation and inverted papilloma of the middle ear have also been reported to be additional risk factors [9] [10] [13]. The co-existence of CSOM with or without cholesteatoma along with malignancy makes the early detection difficult. Many patients present with non-specific signs of chronic inflammation and infection that cause difficulty in reaching a proper clinical diagnosis of this malignant type. Additionally, chronic infections, those often precede the malignancy result in a delay in diagnosis by causing decreased follow-up motivation. Despite the development of increasingly radical surgical procedures and the advances in radiotherapy these tumours retain a poor prognosis. Hence it is very important to detect these lesions very early.

We present a case of squamous cell carcinoma of the middle ear which presented mastoid abscess with intracranial complications which gains relevance in light of the above mentioned diagnostic and therapeutic challenges. Describing this report we would like to emphasise that early diagnosis of malignancy in such a case rests on a high index of suspicion. Our case report also highlights the importance of submission of all mastoid tissues removed at mastoidectomy of unsafe variety of otitis media, however typical the clinical presentation of the disease may be, for histological confirmation of provisional clinical diagnosis.

\section{Case Report}

A 65 years old female was referred from a peripheral hospital with complaints of right sided ear discharge since 10 years of duration. There was associated severe right sided otalgia, hearing loss, and vertigo. She complained of headache with fever since 2 weeks. She underwent ear surgery on right side 30 years back but details were not available. She was a known case of diabetes mellitus on treatment with oral antihypoglycaemics. On clinical examination, patient was febrile and cachexic with unaltered sensorium. There was pale granulation tissue admixed with discharge in the right ear. Post aural swelling was present with tenderness suggestive of mastoid abscess.

Computerised tomography of brain done at a peripheral hospital showed erosion of osteolytic/erosion involving right petrous temporalbone, mastoid air cells and sinus plate associated with soft tissue density lesion in right middle ear cavity, mastoid air cells, attic and external ear (Figure 1).

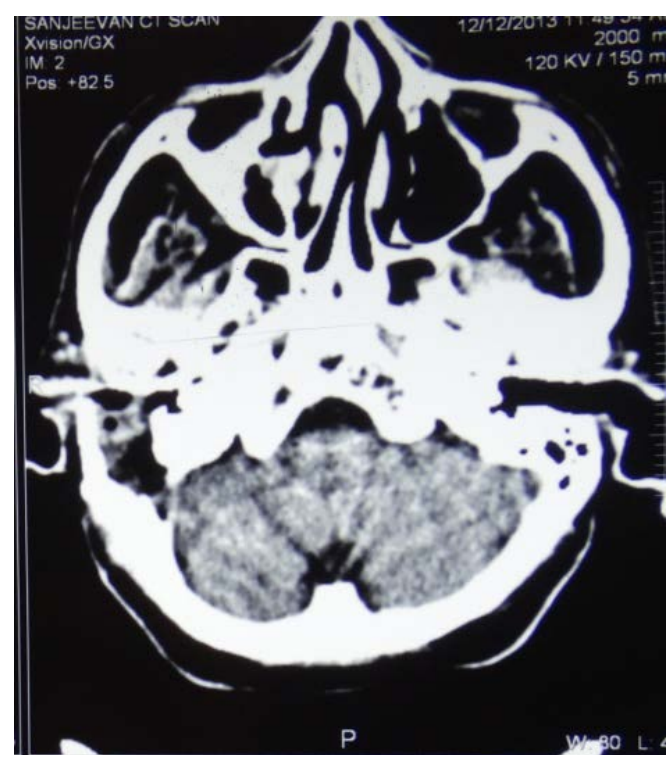

Figure 1. Computerised tomography of brain showing with soft tissue density lesion in right middle ear cavity, mastoid air cells, attic and external ear. 
High resolution computerised tomography (HRCT) of temporal bone done shows peripherally enhancing collection in right mastoid and middle ear cavity with destruction of mastoid and tegmen tympani and sinus tympani involving right sigmoid sinus (Figure 2).

A diagnosis of left chronic suppurative otitis media, complicated by mastoid abscess and meningitis was made, to rule out an intracranial mass lesion.

Patient was posted for tympanomastoid exploration under GA which revealed purulent secretions mixed with keratinous debris and granulations eroding the dural plate and sinus plate. Granulations with bone fragments were removed but as it was invading the dura, disease clearance was not satisfactory (Figure 3). The specimen was sent for histopathological examination along with culture and sensitivity. Mastoid cavity was exteriorised and patient was started on intravenous third generation cephalosporins.

Histopathological examination of the specimen received $2.3 \mathrm{cms}$ in aggregate revealed invasive well differentiated keratinising squamous cell carcinoma (Figure 4). Patient was reevaluated and commenced on palliative

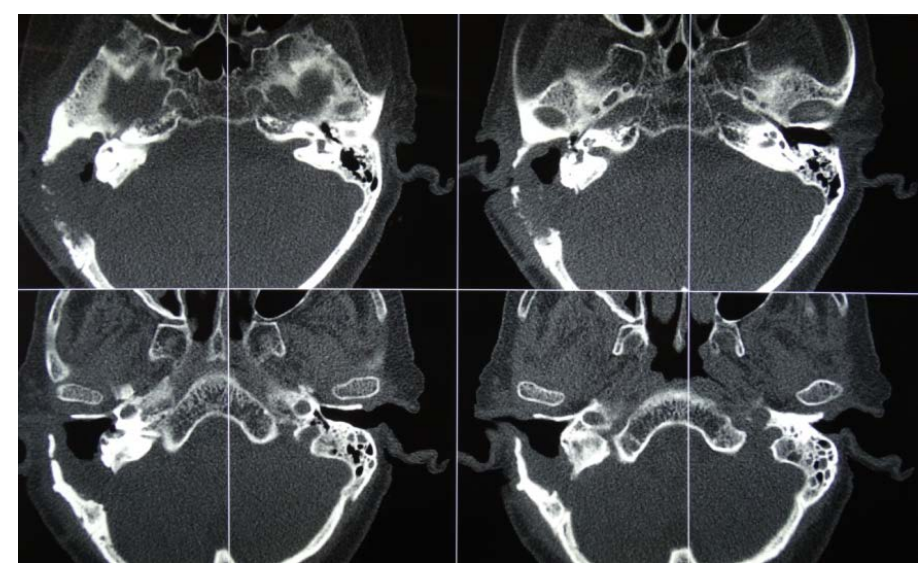

Figure 2. HRCT of temporal bone showing peripherally enhancing collection in right mastoid and middle ear cavity with destruction of mastoid and tegmen tympani and sinus tympani.

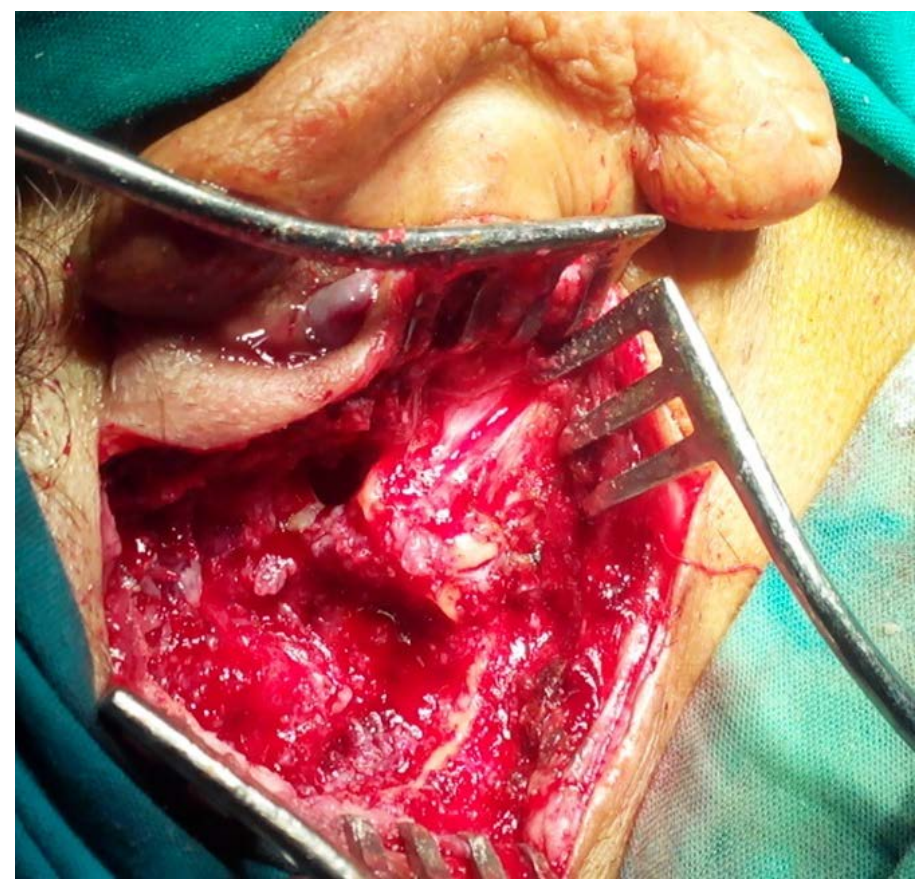

Figure 3. Intraoperative picture showing the keratinous debris, admixed with blood and discharge. 


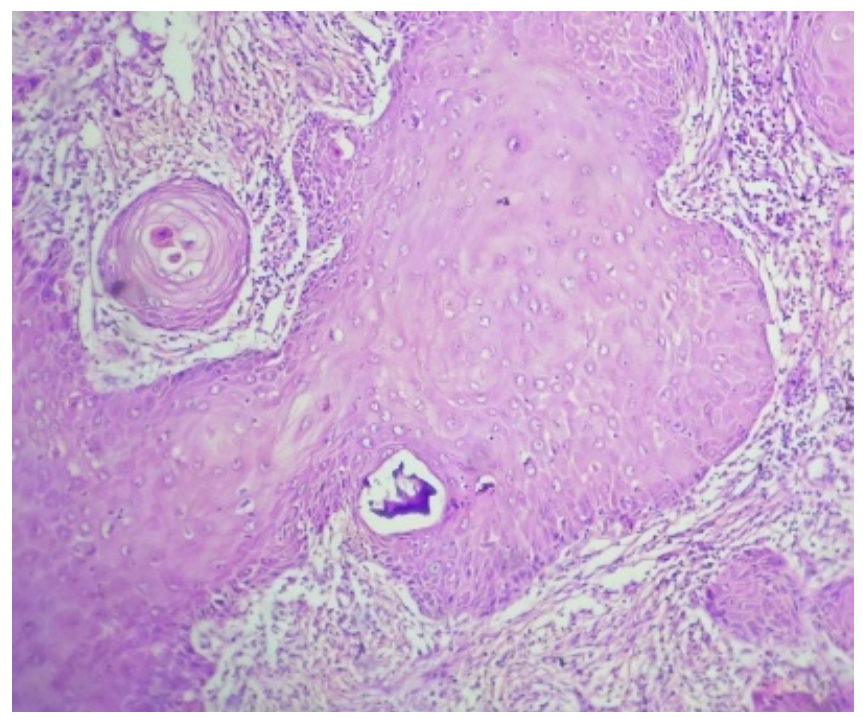

Figure 4. Microscopy showing well differentiated keratinising squamous cell carcinoma.

external beam radiotherapy with a direct lateral field encompassing the EAC, mastoid process with lower border at the angle of the jaw. She was discharged on completion of radiotherapy. Patient was evaluated for 6 months regularly and was subsequently lost for follow up.

\section{Discussion}

Squamous cell carcinoma of the middle ear and temporal bone is a rare malignancy but are associated with considerable morbidity and mortality, both owing to the disease processes themselves and the treatment modalities. Despite the diagnostic advances and therapeutic refinement in this field over the last half century, these malignancies still bear an ominous prognosis.

Squamous cell carcinoma accounts for $60 \%$ to $80 \%$ of all temporal bone malignancies followed by basal cell carcinoma [14]. The disease affect males and females equally, with an age range of 34 - 85 years and an average age of 60 years [15].

The rarity of the disease itself limits the performance of large risk assessment studies as a result of which the aetiology of these tumours is not well defined. It is frequently argued that chronic otitis media is a risk factor for temporal bone malignancy, especially squamous cell carcinoma [14].

The early symptoms of temporal bone carcinoma closely resemble those of chronic suppurative otitis media, including purulent foul-smelling otorrhoea, severe otalgia, bleeding, and pruritus [14]. Since the incidence of malignancy is rare, differentiating between a chronically draining ear with associated inflammation and a malignancy is usually difficult. Other presenting symptoms of malignancy include hearing loss, headaches, tinnitus, vertigo, and aural fullness. Cranial nerve palsies may occur. Spread into the glenoid fossa can result in trismus, and dural involvement can produce severe pain and headache [14].

In our case, patient presented with a classical presentation of chronic ear infection with mastoid abscess and meningitis for which she was immediately taken up for mastoidectomy and abscess drainage. In this case, the delay in diagnosis was obviously due to the nonspecificity of symptoms for which she was treated as a case of chronic inflammation of ear by the private otolaryngologist. Although the diagnosis is rare, early detection can have a considerable impact on outcome [14]. Chronic ear infections not responding to proper antibiotics, bloody or serosanguinous discharge should be evaluated with a suspicion of malignancy. There can be a secondary bacterial infection complicating the diagnosis. Facial nerve palsy, other cranial nerve palsies or headache should be treated considering a possibility of malignancy in such a background.

High-resolution computed tomographic (CT) scans show the bony anatomy of the temporal bone and demonstrate the extent of bony erosion [14]. But the presentation can resemble the intracranial complications of chronic suppurative otitis media that sometimes imaging studies may be less helpful in attaining diagnosis 
unless evaluated properly.

Although a history of chronic otitis media is found in $40 \%$ to $60 \%$ of patients with temporal bone malignancy, it is less clear what role chronic infection may have in the development of malignancy. On the contrary the chronic infections of ear are so common compared to the low frequency of malignancy Carcinoma may arise, in a manner similar to Marjolin's ulcers, from epithelium damaged by chronic otorrhoea or from bacterial toxins that can alter the normal mitotic activity of the epithelial cells. Some authors have found cholesteatoma associated with temporal bone malignancy, but a causal link has not been established [14].

The association of chronic suppurative otitis media with malignancy is not only important when we consider diagnosis but emphasis should be given to subject mastoid tissues removed at mastoidectomy for histopathological evaluation. However typical the presentation of the disease may be, it gains more significance when we consider the fact that early stage of diagnosis definitely make the prognosis better.

There is no universally accepted temporal bone malignancy staging system. The Pittsburgh system is based on radiographic findings and has been correlated successfully with both clinical outcome and histopathology examination of the involved temporal bones [14]. The University of Cincinnati system incorporates radiographic and intraoperative findings and has been successfully used as a guide for determining the extent of temporal bone resection required [14].

The treatment of the disease, surgery or radiotherapy or a combined approach is still controversial as a conclusive study is not yet published owing to the rarity of the disease. The classic surgeries include sleeve resection, lateral temporal bone resection, subtotal temporal bone resection, and total temporal bone resection. While some authors advocate total en bloc removal of the temporal bone surrounding the tumour and others argue for piecemeal removal of gross tumour with preservation of vital neurovascular structures followed by radiation therapy [14]. Mastoidectomy, lateral temporal bone resection (TBR) and subtotal TBR are more appropriate and these techniques showed similar survival in a retrospective review including 144 patients, with a five-year survival of $50 \%, 48.6 \%$ and $50 \%$, respectively [16]. In a retrospective analysis, radical radiotherapy was proposed as the treatment of choice for patients with early stage squamous cell carcinoma of the external auditory canal and middle ear [17]. In addition, surgery, with negative surgical margins if possible, and radiotherapy was recommended in this study as the standard care for cases of advanced-stage disease.

The disparity in the studies itself shows that it is difficult to be certain about treatment results for mastoid squamous carcinoma from the literature. But in general, the treatment of squamous cell carcinoma of the temporal bone comprises surgical excision possibly followed by radiation. The prognosis of the disease remains usually bad owing to the late presentation which is even worse in cases with facial nerve paralysis, positive tumour margins, dural involvement, and regional lymph node involvement [14].

\section{Conclusion}

This case report highlights a rare and aggressive tumor which is associated with chronic suppurative otitis media which is in fact a very common disease that every practitioner encounters. Early diagnosis of malignancy in such a case rests on a high index of suspicion. Early diagnosis, detection and management are the simplest and most effective measures to increase patient survival in these cases. We have tried to highlight how closely the disease mimicked mastoid abscess and meningitis. Our case report also stresses on the significance of submission of mastoid tissues in each case of mastoidectomy for histopathological evaluation as the clinical evaluation and imaging may sometimes prove less useful in detection. Presenting this case, we expect the medical practitioners to have a prompt workup and evaluation for those cases of chronic inflammation of ear which are not responding to treatment.

\section{References}

[1] Arriaga, M., Hirsch, B.E., Kamerer, D.B. and Myers, E.N. (1989) Squamous Cell Carcinoma of the External Auditory Meatus (Canal). Otolaryngology_Head and Neck Surgery, 101, 330-337.

[2] Arena, S. and Keen, M. (1988) Carcinoma of the Middle Ear and Temporal Bone. American Journal of Otology, 9, 351-356.

[3] Ostfeld, E., Segal, M. and Czernobilsky, B. (1981) Malignant External Otitis: Early Histopathotogic Changes and Pathogenic Mechanism. Laryngoscope, 91, 965-970. http://dx.doi.org/10.1288/00005537-198106000-00014

[4] Cohen, D., Friedman, P. and Eilon, A. (1987) Malignant External Otitis versus Acute External Otitis. Journal of La- 
ryngology and Otology, 101, 211-215. http://dx.doi.org/10.1017/S0022215100101550

[5] Cohen, D. and Friedman, P. (1987) The Diagnostic Criteria of Malignant External Otitis. Journal of Laryngology and Otology, 101, 216-221. http://dx.doi.org/10.1017/S0022215100101562

[6] Babiatzki, A. and Sade, J. (1987) Malignant External Otitis. Journal of Laryngology and Otology, 101, 205-210. http://dx.doi.org/10.1017/S0022215100101549

[7] Rodriguez Paramas, A., Gil Carrasco, R., Arenas Britez, O. and Yurrita Scola, B. (2004) Malignant Tumours of the External Auditory Canal and of the Middle Ear. Acta Otorrinolaringológica Española, 55, 470-474.

[8] Yeung, P., Bridger, A., Smee, R., Baldwin, M. and Bridger, G.P. (2002) Malignancies of the External Auditory Canal and Temporal Bone: A Review. ANZ Journal of Surgery, 72, 114-120. http://dx.doi.org/10.1046/j.1445-2197.2002.02313.x

[9] Martinez Subias, J., Dominquez Ugidos, L.J., Urpegui Garcia, A., Sancho Serrano, E., Royo Lopez, J., Millan Guevara, J. and Valles Verela, H. (1998) Middle Ear Carcinoma. Acta Otorrinolaringológica Española, 49, 234-246.

[10] Maran, A.G.D. and Jacobson, I. (1990) Tumours of the Ear. In: Maran, A.G. and Stell, P.M., Eds., Clinical Otolaryngology, 3rd Edition, Blackwell Scientific Publications, Hoboken, 464-474.

[11] Newhart, H. (1917) Primary Carcinoma of the Middle Ear: Report of a Case. Laryngoscope, 27, 543-555. http://dx.doi.org/10.1288/00005537-191707000-00002

[12] Pizzo, P.A., Freifeld, A.G., Meyer, J. and Walsh, T. (1993) Infection in the Cancer Patient. In: DeVita, V.T., Hellmann, S. and Rosenberg, S.A., Eds., Cancer: Principle and Practices of Oncology, 4th Edition, Vol. 62, 2292-2528.

[13] de Filippis, C., Marioni, G., Tregnaghi, A., Marino, F., Gaio, E. and Staffieri, A. (2002) Primary Inverted Papilloma of the Middle Ear and Mastoid. Otology \& Neurotology, 23, 555-559. http://dx.doi.org/10.1097/00129492-200207000-00027

[14] Decker, B.C. (2003) Glasscock-Shambaugh Surgery of the Ear. Vol. 1, 5th Edition, PMPH-USA, 743-754.

[15] World Health Organization (2005) Pathology and Genetics of Head and Neck Tumours IARC WHO Classification of Tumours Series Vol. 9 of World Health Organization Classification of Tumours. IARC Press, Lyon, 349.

[16] Prasad, S. and Janecka, I.P. (1994) Efficacy of Surgical Treatments for Squamous Cell Carcinoma of the Temporal Bone: A Literature Review. Otolaryngology-Head and Neck Surgery, 110, 270-280. http://dx.doi.org/10.1016/S0194-5998(94)70769-3

[17] Ogawa, K., Nakamura, K., Hatano, K., et al. (2007) Treatment and Prognosis of Squamous Cell Carcinoma of the External Auditory Canal and Middle Ear: A Multi-Institutional Retrospective Review of 87 Patients. International Journal of Radiation Oncology, Biology, Physics, 68, 1326-1334. http://dx.doi.org/10.1016/j.ijrobp.2007.01.052 
Scientific Research Publishing (SCIRP) is one of the largest Open Access journal publishers. It is currently publishing more than 200 open access, online, peer-reviewed journals covering a wide range of academic disciplines. SCIRP serves the worldwide academic communities and contributes to the progress and application of science with its publication.

Other selected journals from SCIRP are listed as below. Submit your manuscript to us via either submit@scirp.org or Online Submission Portal.
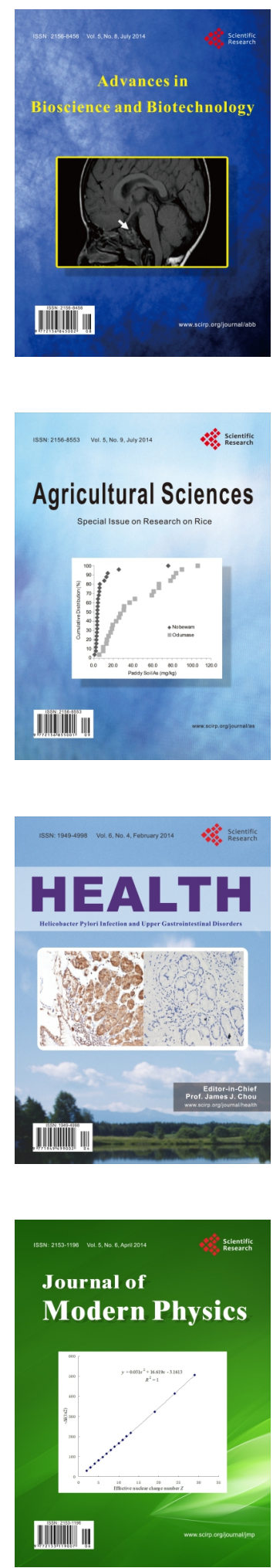
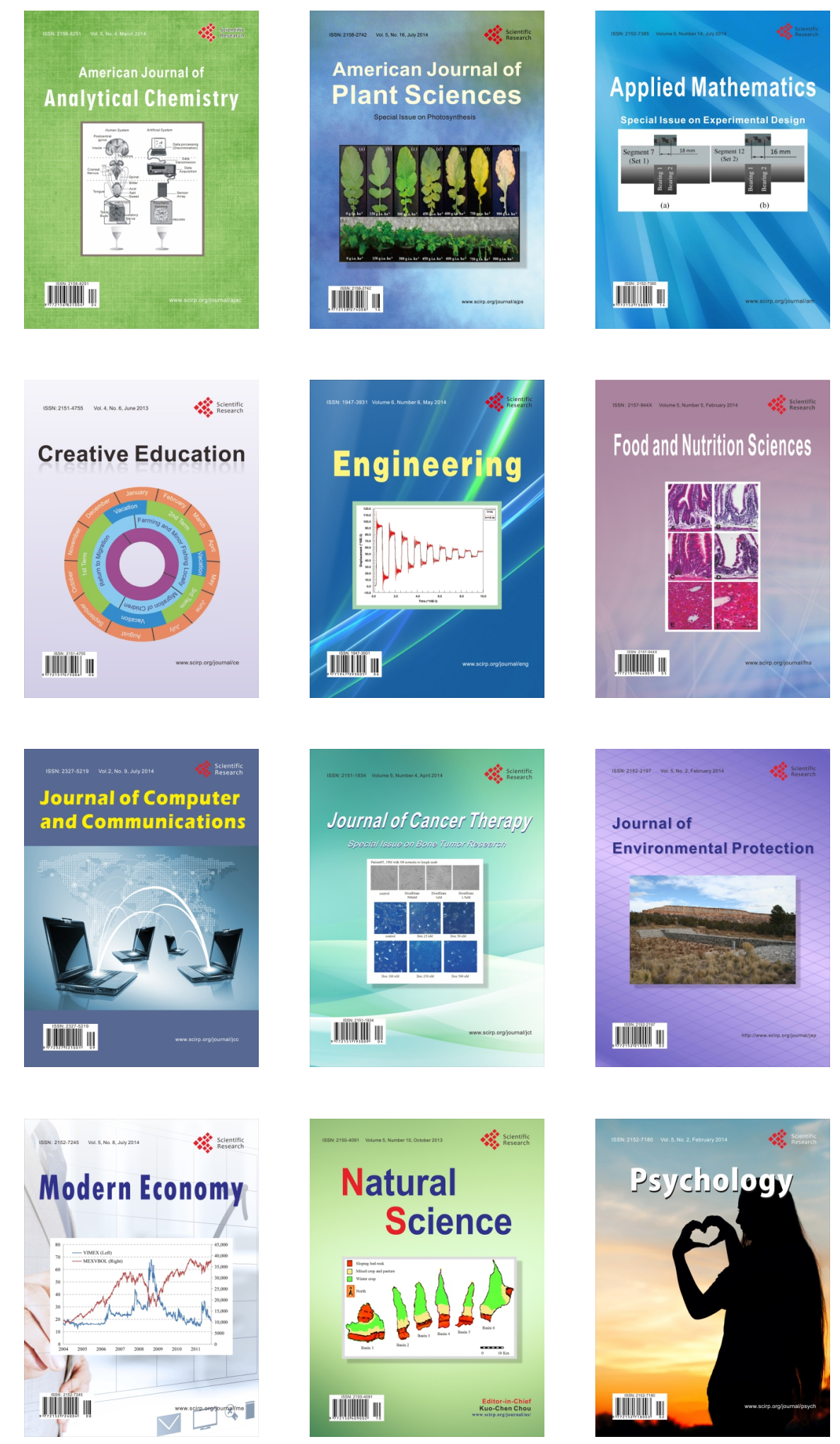